\title{
HISTÓRIA DAS MULHERES NA ARTE: AUTORRETRATO COMO ESCRITA DE SI
}

\author{
HISTORY OF WOMEN IN ART: SELF-WRITING AS A WRITING
}

Fernanda Reis ${ }^{1}$

\begin{abstract}
RESUMO: O presente artigo é parte da Tese de Doutorado intitulada Lídia Baís: Imagens da Transgressão Feminina na História (1920-1940), ainda em processo de escrita. Pretende-se analisar, compreender e problematizar o processo de silenciamento e ocultamento das mulheres na História, bem como, nas Artes Plásticas. Compreender o que determina esse ocultamento feminino na arte ocidental é preocupação primeira desse estudo. No segundo momento pretende-se analisar os mecanismos de resistência e ressignificação do ser mulher através da produção de autorretratos. Compreendemos que a produção de autorretratos nas artes para as mulheres tem um sentido de resistência quando as mesmas se utilizam dele para ressignificar e reescrever suas histórias, bem como o utilizam como um processo de reconhecimento de si.
\end{abstract}

Palavras-Chave: História. Arte. Escrita de si

ABSTRACT: This article is part of the PhD thesis entitled Lídia Baís: Images of Female Transgression in History (1920-1940), still in the process of writing. The aim is to analyze, understand and problematize the process of silencing and hiding women in history, as well as in the plastic arts. Understanding what determines this female concealment in Western art is the primary concern of this study. In the second moment we intend to analyze the mechanisms of resistance and resignification of the woman being through the production of self-portraits. We understand that the production of self-portraits in the arts for women has a sense of resistance when they use it to resignify and rewrite their stories, as well as use it as a process of self-recognition.

Keywords: History. Art. Writing for you

A arte, só ela tem o poder de transformar aqueles pensamentos enjoados sobre o horror e o absurdo da existência em representações com as quais é possível viver: são elas o sublime, enquanto domesticação artística do horrível, e o cômico, enquanto descarga artística da náusea do absurdo.

(Nietzsche- O nascimento da tragédia)

\footnotetext{
${ }^{1}$ Graduada em História pela Universidade Federal de Mato Grosso do Sul. Mestre em História pela Universidade Federal da Grande Dourados. Doutoranda em História pela Universidade Federal da Grande Dourados. Autora do livro: Lídia Baís, Arte, vida e metamorfose, publicado pela Editora da UFGD (EdUFGD), membro do Laboratório de estudos de Gênero, História e Interculturalidade (LEGHI), vinculado a Cátedra UNESCO.
} 


\section{HISTORRIA}

HISTÓRIA DAS MULHERES NA ARTE: AUTORRETRATO COMO ESCRITA DE SI

Fernanda Reis

A história das mulheres emerge como campo de estudo importante e necessário, considerando que os papéis sociais de homens e mulheres foram historicamente construídos com visível imposição do poder masculino sobre os direitos sociais das mulheres. O processo de dominação masculina impõe-se, sobretudo, no campo da cultura, da política, da religião, da ciência e também da arte. Para Pierre Bourdieu:

Também sempre vi na dominação masculina, e no modo como é imposta e vivenciada, o exemplo por excelência desta submissão paradoxal, resultante daquilo que eu chamo de violência simbólica, violência suave, insensível, invisível a suas próprias vítimas, que se exerce essencialmente pelas vias puramente simbólicas da comunicação e do conhecimento, ou, mais precisamente, do desconhecimento, do reconhecimento ou, em última instância, do sentimento (BOURDIEU, 2009, p. 8).

Michelle Perrot em Minha História das Mulheres (2007) levanta uma questão que se refere às produções femininas do século XIX, quando destaca a pouca produção de registros nos arquivos públicos que narrem e ou ajudem historiadores e historiadoras a pensar o lugar das mulheres nesses espaços de poder. Esses arquivos normalmente eram destinados a atos de administração e poder, lugar exclusivamente frequentado por homens. Já nos chamados arquivos familiares, os diários e correspondências íntimas, comumente são alvos de destruição das histórias do cotidiano, especialmente das memórias e dos sentimentos femininos. Isso, segundo, Perrot, dificultou, durante longo período, a produção de uma escrita da história das mulheres.

A História, escrita essencialmente pelos homens, teceu uma historiografia do silêncio em relação às mulheres. Vista até o século $X X$ como um campo de pesquisa que se ocupou dos grandes eventos, das grandes guerras, da política e economia e dos renomados heróis, não havia lugar para as mulheres nesse campo científico. A elas era destinado o silêncio, a clausura do lar, os afazeres domésticos. A "natureza" Ihes impunha a difícil tarefa da maternidade, a responsabilidade da organização doméstica, o espaço privado era delas por excelência. A história das mulheres dependeu das representações dadas pelos homens. O que se tem até o século XX é 


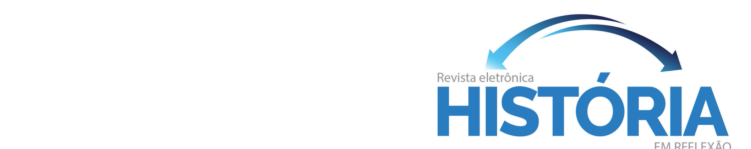

HISTÓRIA DAS MULHERES NA ARTE: AUTORRETRATO COMO ESCRITA DE SI

Fernanda Reis

uma história escrita por homens que falam sobre mulheres numa ótica falocêntrica e excludente, que impõe o silêncio e o obscurantismo às mulheres.

O papel destinado às mulheres envolvia, sobretudo, o bom desempenho feminino como esposa e mãe. Em caso de incapacidade de realizar qualquer uma dessas atividades, inevitavelmente a mulher era entregue à marginalização. As mulheres de "boa família" deveriam casar cedo, gerar filhos saudáveis e zelar pela educação dos mesmos, bem como era sua a responsabilidade pelo bom andamento do lar. O homem, provedor da família, tinha sob sua tutela a esposa e os filhos, que deviam obediência absoluta. Os assuntos políticos e econômicos ficavam a cargo dos chefes de família que eram considerados os únicos capazes de pensar e compreender essas questões, pois a eles cabia a tarefa da racionalidade, enquanto para as mulheres a "natureza" sensível e dócil impedia que elas participassem das discussões políticas e econômicas.

O papel designado à mulher resumia-se em ser boa esposa e excelente mãe. Seu fracasso nessa área marginalizava-a. A falta de filhos era problema exclusivo seu, a infecundidade jamais decorria do homem, o sexo potente, segundo Aristóteles. O prazer sexual era permitido somente às prostitutas, porque a paixão, segundo os ditames da época, poderia colocar em risco o santo casamento. As prostitutas, mulheres de "vida fácil", podiam dançar, cantar e vestir roupas provocante (COLLING, 2010, p. 37).

Dizer que as mulheres foram silenciadas e ocultadas da história não significa dizer que não fizeram parte dela. O que ocorre é que por muito tempo a história foi escrita e registrada pelos homens, negando a existência e a importância das mulheres tanto de forma individual como coletiva na construção da sociedade. Na obra As mulheres e a história: uma introdução teórica metodológica (2012) o historiador Losandro Tedeschi destaca o quanto o discurso sobre a fragilidade feminina influenciou na produção historiográfica até meados do século XX. Observa ainda a importância de inúmeros trabalhos que ao longo dos anos vem sendo realizados por historiadoras e historiadores que se debruçam nos estudos de gênero. $A$ inserção da mulher na produção historiográfica faz-se necessária para reescrever o passado e compreender as diferentes formas da mulher ser e estar no mundo.

Enquanto narrativa, a História constitui-se como tradição e cânone do qual as mulheres não participaram de modo visível pelos caminhos REHR| Dourados, MS | v. 12 | n. 23| p. 68-83 jan. / jun. 2018 


\begin{abstract}
HISTÓRIA
HISTÓRIA DAS MULHERES NA ARTE: AUTORRETRATO COMO ESCRITA DE SI

Fernanda Reis

tradicionais do fazer histórico. A teoria feminista procura investigar a fundamentação dessa ausência. É um modo de teorização que surge com pensadoras e revolucionárias, como por exemplo, Mary Wollstonecraft, em seus Escritos Políticos, nos quais critica o sexismo dos pensadores homens (como o de Rousseau), ou como Rosa de Luxemburgo com sua originalidade de pensar o socialismo alemão, e que evoluiu até meados do século $X X$ (presente nas concepções e práticas pedagógicas nas escolas) como teóricas que nem Simone de Beauvoir em seu o Segundo Sexo, Alterando para os direitos das mulheres na base de uma reivindicação do ser o do pensar à vida pública e ao universo do discurso e do poder (TEDESCHI, 2012, p. 11).
\end{abstract}

Segundo Colling (2010), a construção de um discurso que insere a mulher em um lugar subalterno na história advém da ausência delas na produção do discurso historiográfico. Para a historiadora, é necessário libertar a História falando de homens e mulheres em nível de igualdade. A História das mulheres tem como função reconhecer o processo histórico de exclusão e silenciamento desses sujeitos ocultos.

Os historiadores fizeram a historiografia do silêncio. A História transformou-se em relato que esqueceu as mulheres, como se, por serem destinadas à obscuridade da reprodução, inenarrável, elas estivessem fora do tempo, fora do acontecimento. Mas elas não estão sozinhas nesse silêncio profundo. Elas estão acompanhadas de todos aqueles que foram marginalizados pela história como os negros, os índios, os velhos, os homossexuais, as crianças, etc. Portanto, escrever a história das mulheres é libertar a história. Libertar a história das amarras das metanarrativas modernas, falocêntricas (COLLING, 2010, p. 42).

Construir um discurso sobre os lugares femininos na sociedade moderna a partir de seus modos de resistência e transgressão entende-se a necessidade de retomar a discussão sobre a história das mulheres referente à primeira metade do século XX e a importância delas na construção dessa sociedade. Esse debate perpassa pela compreensão dos mecanismos de fuga e resistência empreendida por elas também como meio de inserção nesse espaço. A Arte também é atravessada pela história do silenciamento e do ocultamento das mulheres, é um dos tantos espaços em que foram silenciadas e viram a necessidade de se reinventar a partir da ressignificação desse espaço.

A História da Arte não se diferencia em nada desse processo de silenciamento. Ainda hoje é marcada pela predominância do masculino, seja por meio da legitimação dos cânones artísticos, pela presença maciça de homens nos museus ocupando REHR| Dourados, MS | v. 12 | n. 23| p. 68-83 jan. / jun. 2018 


\section{HISTÓRIA \\ HISTÓRIA DAS MULHERES NA ARTE: AUTORRETRATO COMO ESCRITA DE SI \\ Fernanda Reis}

funções como artistas, curadores, coordenadores e também por meio da divulgação midiática. Observamos uma constante masculina que insiste em silenciar a produção feminina. Paira sobre o tempo histórico um discurso e uma prática que evidencia a arte feminina como uma arte menor. Os espaços sociais, ainda limitados às mulheres, são predominantemente masculinos, brancos, heteronormativos, todavia excludentes. O espaço de produção da arte também segue a lógica patriarcal e dominante que silencia e nega uma quantidade infinita de mulheres artistas, que diferentemente dos homens não conseguem muitas vezes ter visibilidade em seus trabalhos. Quando conquistam essa visibilidade prevalece um discurso que de algum modo insere a presença masculina por trás do sucesso da mulher artista.

Essa lógica nos diz que as mulheres precisam ser "governadas", as artistas em especial são reconhecidas na História da Arte como apêndice de alguém, são filhas, esposas, amantes, mães que tem suas produções justificadas a partir de suas relações com outros homens artistas. A arte feminina constantemente é colocada à prova, sobretudo a capacidade de produção e realização de um trabalho mais complexo.

A ausência de várias artistas mulheres dos cânones da história da arte
e as particularidades enfrentadas pelas artistas contemporâneas que
desenvolvem práticas questionadoras são outros termos
fundamentais de discussão para a construção desse enfoque. As
narrativas da história, sendo uma dela a arte, são modos de
construção da memória social e de legitimação de discursos
"verdadeiros" sobre os indivíduos que podem ser continuamente
transformados (TVARDOVSKAS, 2015, p. 32).

Ao se valer da arte como um espaço de resistência e sendo a obra de arte um espaço capaz de fazer a artista tornar-se outra, a arte em si, acrescenta diferentes perspectivas ao sentido de existência no mundo. Ao inserir-se na obra de arte, a artista passa a (re)existir de um modo outro, sendo ela e ao mesmo tempo outra, (re)significando sua existência a partir de suas próprias experiências e vivências.

Além disso, formar por formar não significa formar o nada- conteúdo de toda formação especificamente tal é a própria pessoa do artista. Com isso não se deve entender que a pessoa do artista entra na obra como objeto de narração, a pessoa que forma é declarada pela obra formante como estilo, modo de formar, a obra nos conta, exprime a personalidade de seu criador na própria trama de seu consistir, o 


\section{HISTÓRIA \\ HISTÓRIA DAS MULHERES NA ARTE: AUTORRETRATO COMO ESCRITA DE SI}

Fernanda Reis

artista vive a obra como traço concreto e personalíssimo de ação. (ECO, 2016, p. 15).

Essa ação na qual a artista vive compõem-se de características que exprimem, sobretudo uma memória não apenas individual, mas coletiva e social. A Arte, sendo subjetiva é problematizada pela criadora de modo que sua produção é ao mesmo tempo transformada e transformadora da própria realidade:

Conteúdo da obra é a própria pessoa do criador que, ao mesmo tempo, se faz forma, pois constitui o organismo como estilo (que pode ser reencontrado a cada leitura interpretante), modo com o qual a obra consiste. Assim sendo, o próprio sujeito de uma obra não é outra coisa senão um dos elementos nos quais a pessoa expressou-se fazendose forma (ECO, 2016, p. 15).

Desse modo, entendemos a arte enquanto um sistema de signos a partir do que Charles Sanders Peirce (2010), conceitua como tal. Para o semiólogo norteamericano um signo é alguma coisa que tem um significado e uma representação de algo para alguém, de modo que essa representação dirige-se a esse alguém como um objeto capaz de criar na mente um signo equivalente ou além do representado inicialmente, portanto, um Signo é parte de um Signo (2010, p. 47):

Um signo é um ícone, um índice ou um símbolo. Um ícone é um signo que possuiria o caráter que o torna significante, mesmo que seu objeto não existisse, tal como um risco feito a lápis representando uma linha geométrica. Um índice é um signo que de repente perderia seu caráter que o torna um signo se seu objeto fosse removido, mas que não perderia esse caráter se não houvesse interpretante. Tal é, por exemplo, o caso de um molde com um buraco de bala como signo de um tiro, pois sem o tiro não teria havido buraco; porém, nele existe um buraco, quer tenha alguém ou não a capacidade de atribuí-lo a um tiro. Um símbolo é um signo que perderia o caráter que o torna um signo se não houvesse um interpretante. Tal é o caso de qualquer elocução de discurso que significa apenas por força de compreender-se que possui essa significação (PEIRCE, 2010, p. 74).

Assim, a arte sendo um signo pressupõe uma reflexão complexa e subjetiva. E por ser subjetiva, transcende o lógico e o óbvio, aquilo que está posto. $O$ artista não pode copiar um gramado banhado de sol, mas pode sugeri-lo. Exatamente como o fará, em um caso ou em outro, é segredo seu, mas as poderosas palavras que tornam a mágica possível são do conhecimento de todos os artistas: relações (GOMBRICH, 1995, p. 40). 


\section{HISTÓRIA}

HISTÓRIA DAS MULHERES NA ARTE: AUTORRETRATO COMO ESCRITA DE SI

Fernanda Reis

Para o historiador da Arte Ernest Gombrich (1995), por mais que a artista se utilize de técnicas, de jogos de luz e ainda que consiga produzir uma paleta de cores capaz de representar uma imagem tão próxima da realidade, ainda assim nunca é a realidade em si. Para Gombrich ao produzir uma imagem em uma tela, a artista passa por um processo de reconhecimento de uma mensagem visual que the é dada anteriormente:

Seria interessante se alguma verdadeira autoridade investigasse cuidadosamente a parte que a memória tem na pintura. Olhamos para o objeto com um olhar atento, depois para a paleta e em terceiro lugar para a tela. A tela recebe a mensagem despachada, via de regra, alguns segundos antes pelo objeto natural. Foi transmitida em código. Passou de luz para cor. Chega à tela sob a forma de um criptograma. Até que seja posta em relação completa com tudo o mais que se encontra na tela não pode ser decifrada ou seu significado feito aparente, traduzido uma vez mais de mero pigmento em luz. E a luz, dessa vez, não é da Natureza, mas da Arte (GOMBRICH, 1995, p. 41).

Assim, essa recriação criptografada de uma imagem anteriormente percebida, não é necessariamente algo real e concreto, mas pode vir de suas próprias subjetividades e de suas experiências pessoais. Através dessa criação artística que se faz por meio de um sistema de signos é possível perceber o mundo, a sociedade, as questões individuais que atravessam as experiências da criadora. Ao invés de explorarem o mundo visível, sondam os mistérios da mente, do inconsciente, ou estudam a nossa reação a formas abstratas (GOMBRICH, 1995, p. 35).

Sendo a arte um lugar de resistência é através dela que a criadora existe em um constante processo de autotransformação. E ao autotransformar-se, a artista modifica o mundo a sua volta criando diferentes formas de interpretação não só da obra, mas de todo um sistema social instituído anteriormente:

É possível que, diante de uma obra de arte, eu compreenda os valores que ela comunica e que, ainda assim, não os aceite. Nesse caso, posso discutir uma obra de arte no plano político e moral e posso rejeitá-la, contestá-la justamente porque é uma obra de arte. Isso significa que a Arte não é o absoluto, mas uma forma de atividade que estabelece uma relação dialética com outras atividades, outros interesses, outros valores. Diante dela, na medida em que reconheço a obra como válida, posso operar minhas escolhas, eleger meus mestres (ECO,2016, p. 24). 


\section{HISTORIA}

HISTÓRIA DAS MULHERES NA ARTE: AUTORRETRATO COMO ESCRITA DE SI

Fernanda Reis

Nesse sentido, entendemos que esse sistema de signos e esse modo de resistência através da arte se constituem de formas distintas quando produzida por homens e mulheres. Ainda que a produção artística masculina também tenha um caráter contestador, recriador do mundo e dos sistemas impostos essa produção comumente naturaliza uma visão falocêntrica desse mundo recriado. Considerando o lugar privilegiado de produção que os homens historicamente ocupam, os discursos predominantes dizem respeito a um sistema de significações bem específicos, onde esse modo de ver o mundo é ainda predominantemente masculino. É através dessas representações que se institui uma verdade como única possível e a partir delas é que se exerce o poder, de modo que esse poder estabelecido privilegia e reforça um discurso e um olhar masculino sobre a produção artística universal. Esse sistema produz efeitos nos modos de ver e entender as questões de gênero e sexualidade, por exemplo.

Partindo desse pressuposto, é possível afirmar que as imagens produzidas pela arte ocidental colocaram as mulheres como objeto de contemplação, produziu um discurso sobre o feminino e a sexualidade privilegiando um olhar masculino sobre o corpo feminino. Se a produção artística pode ser considerada um sistema de signos e esses por sua vez são produzidos a partir de uma ideia anteriormente concebida, ao reproduzir constantemente um tipo específico do feminino, então podemos afirmar que essa arte considerada universal moldou a concepção do que é arte e do que é ser artista. Constituiu-se assim, uma rede de saberes e poderes que autorizou o cânone artístico predominantemente masculino.

Nesse sentido, a pergunta que deve ser feita é: as mulheres não foram suficientemente capazes de produzir arte na mesma qualidade e quantidade que os homens? Evidentemente que esta não é uma pergunta difícil de ser respondido se considerarmos a construção cultural das sociedades ocidentais, do modo como o masculino se constituiu enquanto figura visível nos espaços socialmente construídos pela lógica patriarcal. Não apenas nas Ciências, na política, na economia, mas também na arte o patriarcado fez suas vezes e as mulheres nesse espaço de produção foram historicamente silenciadas. Diferentemente do que se tem em vista, as mulheres desde sempre produziram arte. Mulheres artistas também reinventaram os modos de pensar e produzir arte, lançando mão muitas vezes de suas experiências 


\section{HISTÓRIA}

HISTÓRIA DAS MULHERES NA ARTE: AUTORRETRATO COMO ESCRITA DE SI

Fernanda Reis

pessoais para reinventar sua existência e seus modos de estarem no mundo. Se compreendermos que as mulheres estiveram presentes na produção artística em todo o mundo e suas obras são tão relevantes para a História da Arte que fenômeno é esse que nos faz desconhecer e ou negar a existência das mulheres nas artes? Segundo Linda Nochlin:

A culpa não está nos astros, em nossos hormônios, nos nossos ciclos menstruais ou em nosso vazio interior, mas sim em nossas instituições e em nossa educação, entendida como tudo o que acontece no momento que entramos nesse mundo cheio de significados, símbolos, signos e sinais. Na verdade, o milagre é, dadas as esmagadoras chances contra as mulheres ou negros, que muitos destes ainda tenham conseguido alcançar absoluta excelência em territórios de prerrogativa masculina e branca como a ciência, a política e as artes (NOCHILIN, 1971, p. 8).

Entendemos que esse silenciamento e ocultamento das mulheres nas artes são parte de um sistema institucional e educativo que legitima discursos e práticas de dominação masculina. A arte Ocidental não hesitou em representar a figura feminina em suas produções artísticas, de modo que a presença da mulher na arte é reconhecida por meio da exposição de seus corpos como objetos de contemplação. Representadas através da perspectiva masculina, esses corpos, predominantemente nus, ou completamente cobertos, reafirmam um lugar feminino que não condiz com a realidade, são corpos que sequer representam os lugares verdadeiramente ocupados pelas mulheres, legitimando assim, um discurso e um lugar totalmente subordinado a lógica patriarcal.

Ao trazermos para nossa análise o corpo como parte de um sistema instituído, podemos reconhecê-lo de diferentes formas. Michel Foucault em O corpo utópico (2013) destaca que o corpo em princípio seria o contrário de uma utopia ao mesmo tempo em que é o objeto principal de toda ela, cala-se apenas diante do espelho, do cadáver e do amor. O corpo seria uma "topia", um lugar outro ao qual todos estão condenados. Utopia é um lugar fora de todos os lugares, um lugar onde ter-se-ia um corpo sem corpo (2013, p. 8). O corpo, portanto, possui lugares sem lugar, lugares profundos para além da alma, de modo que o corpo não é apenas um corpo, é também um espaço outro, um não lugar. 


\section{HISTÓRIA \\ HISTÓRIA DAS MULHERES NA ARTE: AUTORRETRATO COMO ESCRITA DE SI \\ Fernanda Reis}

Corporeidade para Foucault aparece nessa obra como algo indissociado do espaço, nesse sentido, a experiência do corpo se faz por meio de resultados históricos diversos, de modo que o corpo reduz-se a lugar inevitável, que existe antes e depois da morte.

Meu corpo, topia implacável. E se, por sorte, eu vivesse com ele em uma espécie de familiaridade gasta, como se com uma sombra, ou com as coisas de todos os dias que no fim das contas não enxergo mais e que a vida embaçou; como as chaminés, os tetos que todas as tardes, se ondulam diante de minha janela? No entanto, todas as manhãs, a mesma presença, a mesma ferida; desenha-se aos meus olhos a inevitável imagem imposta pelo espelho: rosto magro, ombros arcados, olhar míope, sem cabelos, realmente nada belo. E é nesta desprezível concha da minha cabeça, nesta gaiola de que não gosto, que será preciso mostrar-me e caminhar; é através desta grade que será preciso falar, olhar, ser olhado; sob esta ele, pele deteriorar (FOUCAULT, 2013, p. 7).

É no corpo e através dele que novos mundos são produzidos. É também por meio da visibilidade e das invisibilidades produzidas dentro do espaço historicamente construído que o corpo torna-se um incessante meio de produção utópica, ao mesmo tempo em que ele é a própria utopia.

A utopia é um lugar fora de todos os lugares, mas um lugar onde eu teria um corpo sem corpo, um corpo que seria belo, límpido, transparente, luminoso, veloz, colossal na sua potência, infinito na sua duração, solto, invisível, protegido, sempre transfigurado; pode bem ser que a utopia primeira, a mais inextirpável no coração dos homens, consista precisamente na utopia de um corpo incorporal (FOUCAULT, 2013, p. 8).

Nesse sentido, reafirmamos que o modo de expor o corpo nas Artes é diferente quando trata-se de homens e mulheres. Esse corpo utópico que se materializa de diferentes formas, em diferentes lugares e "não lugares" toma formas distintas, quando, por exemplo, o corpo feminino é representado pelo olhar masculino e quando esse mesmo corpo se insere em uma obra de arte pelas mãos femininas. Entendemos então que a obra de arte é esse "não lugar", esse lugar outro que o corpo ali representado se encontra:

Meu corpo está, de fato, sempre em outro lugar, ligado a todos os outros lugares do mundo e, na verdade, está em outro lugar que não o mundo. Pois é em torno dele que as coisas estão dispostas, é em 


\section{HISTÓRIA \\ HISTÓRIA DAS MULHERES NA ARTE: AUTORRETRATO COMO ESCRITA DE SI \\ Fernanda Reis \\ relação a ele- e em relação a ele como uma relação a um soberano- que há um acima, um abaixo, uma direita, uma esquerda, um diante, um atrás, um próximo, um longínquo. O corpo é o ponto zero do mundo, lá onde os caminhos e os espaços se cruzam, o corpo está em parte alguma: ele está no coração do mundo, este pequeno fulcro utópico, a partir do qual eu sonho, falo, avanço, imagino, percebo as coisas em seu lugar e também as nego pelo poder indefinido das utopias que imagino. Meu corpo é como a Cidade do Sol, não tem lugar, mas é dele que saem e se irradiam os lugares possíveis, reais ou utópicos (FOUCAULT, 2013, p. 14).}

Ao dizermos que as obras de Arte produzidas por homens e mulheres são distintas e tem um lugar outro na sociedade, estamos dizendo que essa produção feminina é um espaço do outro que foi esquecido, silenciado e apagado pela cultura ocidental. Foucault entende o espaço como uma relação de posições e nesse espaço a vida é comandada por regimes de verdade. A heterotopia para o autor se refere a lugares reais, mas que estão fora dos lugares aceitos, de modo que a própria sociedade produz heterotopias:

Vejamos o que quero dizer. Não se vive em um espaço neutro e
branco; não se vive, não se morre, não se ama no retângulo de uma
folha de papel. Vive-se, morre-se, ama-se em um espaço
quadriculado, recortado, matizado, com zonas claras e sombras,
diferenças de níveis, degraus de escada, vãos, relevos, regiões duras
e outras quebradiças, penetráveis, porosas. Há regiões de passagem,
ruas, trens, metrôs; há regiões abertas de parada transitória, cafés,
cinemas, praias, hotéis, e há regiões fechadas de repouso e moradia.
Ora, entre todos esses lugares que se distinguem uns dos outros, há
os que são absolutamente diferentes: lugares que se opõem a todos
os outros, destinados, de certo modo, a apagá-los, neutralizá-los ou
purificá-lo (FOUCAULT, 2013, p. 19).

Estes outros lugares também são denominados de heterotopias do desvio, apresentam comportamentos que estão fora das condutas aceitas pela sociedade, e é aí que, segundo Foucault, encontram-se os conflitos e as tensões exercidas pelas relações de poder. As heterotopias tem como função primeira, criar um espaço de ilusão que por sua vez, denuncia os espaços que a vida real está confinada. Por outro lado, as heterotopias criam outro espaço real, perfeito e arranjado em contraposição a desordem do nosso próprio espaço.

Mas essas heterotopias biológicas, essas heterotopias de crise, desaparecem cada vez mais e são substituídas por heterotopias de desvio: isto significa que os lugares que a sociedade dispõe em suas 


\section{HISTÓRIA \\ HISTÓRIA DAS MULHERES NA ARTE: AUTORRETRATO COMO ESCRITA DE SI \\ Fernanda Reis \\ margens, nas paragens vazias que a rodeiam, são antes reservados aos indivíduos cujo comportamento é desviante relativamente à média ou à norma exigida. Daí as casas de repouso, as clínicas psiquiátricas, daí também, com certeza as prisões (FOUCAULT, 2013, p. 22).}

Foucault ao pensar esses lugares heterotópicos traz para seu discurso os asilos, os cemitérios, as prisões, os bordéis as colônias. São lugares que servem, sobretudo como dispositivos disciplinares, no entanto, a obra de Arte, embora seja um sistema de signos, uma representação do real, um "não- lugar", ao materializar-se na tela pelas mãos da artista passa a existir e dependendo do modo como essa representação é elaborada pela artista também exerce uma função disciplinar. As mulheres ao serem representadas pelo olhar e pelas mãos masculinas configuram um modelo, um padrão disciplinar sobre o sentido do ser mulher encerra-se ali qualquer outra possibilidade que não a objetificação de seus corpos e sua sexualidade.

É aí, sem dúvida, que encontramos o que de mais essencial existe nas heterotopias. Elas são a contestação de todos os outros espaços, uma contestação que pode ser exercida de duas maneiras: ou como nas casas de tolerância de que Aragon falava, criando uma ilusão que denuncia todo o resto da realidade como ilusão, ou, ao contrário, criando outro espaço real tão perfeito, tão meticuloso, tão bem disposto quanto o nosso é desordenado, mal posto e desarranjado (FOUCAULT, 2013, p. 28).

Por outro lado, as produções femininas comumente libertam seus corpos desse espaço anteriormente instituído. A chamada arte universal tem gênero e cor, corresponde a grupos específicos de homens brancos e ocidentais e inevitavelmente produz um discurso que afeta as noções de gênero, sexualidade e raça em todo o mundo. As interfaces entre imagem e discurso que pesa sobre o corpo e a sexualidade feminina produz uma ideia universal sobre a mulher. Constitui-se assim uma busca incessante sobre uma possível verdade universalizante do ser mulher, do lugar que ela deve ocupar nessa sociedade ocidentalizada.

A luta pelo protagonismo feminino nas artes atravessa o corpo feminino, este muitas vezes utilizado por elas para (re)escrever seu lugar na história, (re)dimensionando os modos como esse corpo foi e está sendo representado a partir de uma perspectiva masculina. O corpo feminino representado e consumido de modo dócil e disciplinado pela cultura ocidental, ele mesmo é utilizado pelas mulheres como mecanismo de resistência, cria linhas de fuga que emergem das experimentações do 


\section{HISTÓRIA}

HISTÓRIA DAS MULHERES NA ARTE: AUTORRETRATO COMO ESCRITA DE SI

Fernanda Reis

feminino nas práticas do reconhecimento de si. $A$ arte se compõe, assim, como um dos lugares do social em que são geradas múltiplas resistências e onde se tensionam complexamente os enunciados normativos (TVARDOVSKAS, 2015, p. 27).

No campo das artes o autorretrato insere-se no contexto feminino como uma escrita de si. Os autorretratos permitirão duplicar o duplo, jogar um duplo contra o outro, e assim escapar do império do duplo especular-se, reconstituir-se, regenerarse, parir a si mesma, afirmando uma vida mais potente que a loucura e a morte (CHIARA, 2015, p. 67).

Ao pintar, esculpir e fotografar suas experiências, as mulheres atravessam a barreira do silenciamento, falam através da arte e a usam como instrumento de denúncia.

No gênero autorretrato interessa, por conseguinte, e sobretudo, o rompimento das semelhanças do amplo gênero autobiográfico, já que, trabalhando com diversas faces de diferenciados momentos, estranhamentos e rupturas com conteúdos fixos, ou cronologias estáveis, escreve (pinta, esculpe) para o corpo novas superfícies, aspectos diferenciais, recomeços, retomadas, citações intertextuais e intratextuais como se fossem variadas reescrituras do eu, como novas tatuagens escritas sobre antigas. Nesse sentido, o reflexo especular do pronome Eu (com maiúscula), como é pensado no senso comum, está rasurado pela intercorrência dessas faces diversas, das coisas do mundo, dos outros, do circunstancial, o que torna rarefeita a percepção da primeira pessoa sobre si mesma como árduo trabalho de pintar sobre água (CHIARA, 2015, p. 66).

Ao autorretratar-se as mulheres assumem outro lugar no meio artístico, sobretudo no mundo, saem da condição de objeto e tornam-se protagonistas de suas vidas fazendo falar aquilo que está silenciado, oculto, esquecido. Ressignificam reescrevem e perpetuam sua existência na obra de arte. Entendemos essa pratica como um modo de dar voz a si mesma.

Contar sua história dirá, então, respeito não à representação de si, fixação de uma biografia, mas a ficcionalização de um corpo cujas aparição e desaparição revelam que esta já não pode ser entendido como organismo, não pode ser visualizado como substância, mas sobrevive como suporte de algo que passa ali e por ali vaza (CHIARA, 2015, p. 60).

Sobre a escrita de si Foucault destaca a importância da vida construída como autora de si mesmo, propõe uma ética intelectual de desprendimento de si própria 


\section{HISTÓRIA \\ HISTÓRIA DAS MULHERES NA ARTE: AUTORRETRATO COMO ESCRITA DE SI \\ Fernanda Reis}

como meio de autorecosntrução em um processo permanente. Ao observar que a conduta moral exige transformação de si mesmo em sujeito ético, o autor destaca que não havendo a construção desse sujeito ético não há uma prática de si. Centra-se na escrita como estratégia prática na construção de si.

Nenhuma técnica, nenhuma aptidão profissional podem adquirir-se sem exercício; também não se pode aprender a arte de viver [...]que é preciso entender como um adestramento de si por si mesmo: aí residia um dos princípios tradicionais aos quais, desde há muito, os Pitagóricos, os Socráticos, os Cínicos tinham dado grande importância. Parece não haver dúvida que, entre todas as formas que tomou este adestramento (e que comportava abstinências, memorizações, exames de consciência, meditações, silêncio e escuta de outro), a escrita - o facto de se escrever para si e para outrem - só tardiamente tenha começado a desempenhar um papel considerável (FOUCAULT, 1992, p. 130).

Para Foucault a ascese, ou o adestramento de si por si mesmo é um trabalho que não está somente sobre os atos, mas, sobretudo no pensamento, onde se encontram as abstinências, memorizações, os exames de consciência, a meditação. O sujeito, portanto não é à base do processo de decifração, mas ainda o lugar onde regras se tornam vivas na memória. Assim, podemos dizer que não é o deciframento de si que é propriamente importante, mas sim, a memória do que se fez, e do que se tem que fazer. A escrita se insere num campo estratégico no ato de meditação, escrever, portanto, é apossar-se de uma lista de preceitos e mandamentos que quem escreve utiliza para auxiliar a memória. É através da escrita que quem escreve melhora a compreensão de si mesmo.

A escrita de si mesmo aparece aqui claramente na sua relação de complementaridade com a anacorese: atenua os perigos da solidão; dá o que se viu ou pensou a um olhar possível; o fato de se obrigar a escrever desempenha o papel de um companheiro, ao suscitar o respeito humano e a vergonha; podemos pois propor uma primeira analogia: aquilo que os outros são para o asceta numa comunidade, sê-lo-á o caderno de notas para o solitário. Mas, simultaneamente, uma segunda analogia se coloca referente à prática da ascese como trabalho não apenas sobre os atos mas, mais precisamente, sobre o pensamento: o constrangimento que a presença alheia exerce sobre a ordem da conduta, exercê-lo-á a escrita na ordem dos movimentos internos da alma; neste sentido, ela tem um papel muito próximo do da confissão ao diretor, do qual Cassiano dirá, na linha da espiritualidade avagriana, que deve revelar, sem exceção, todos os 


\section{HISTÓRIA \\ HISTÓRIA DAS MULHERES NA ARTE: AUTORRETRATO COMO ESCRITA DE SI \\ Fernanda Reis \\ movimentos da alma (omnes cogitationes) (FOUCAULT, 1992, p. 130).}

A escrita, segundo Foucault, é uma prática e um processo de reconhecimento de si. Ao anunciar a morte do autor no sentido de apagamento das características individuais do escritor, Foucault destaca que as relações entre autor, texto e leitor, neutralizam os sinais da sua identidade particular, de modo que as relações entre eles são substituídas pelas relações entre linguagem e sujeitos. Autor e leitor são nomes de uma posição do sujeito dentro da estrutura de linguagem.

Séneca insiste nisso: a prática de si implica a leitura, pois não é possível tudo tirar do fundo de si próprio nem armar-se por si só com os princípios de razão indispensáveis à conduta: guia ou exemplo, o auxílio dos outros é necessário. Mas não se deve dissociar leitura e escrita; deve-se "recorrer alternadamente" a estas duas ocupações, e "temperar uma por meio da outra". Se escrever demais esgota (Séneca pensa aqui no trabalho do estilo), o excesso de leitura dispersa: "Fartura de livros, barafunda do espírito". A passar sem descanso de livro para livro, sem nunca parar, sem voltar de tempos a tempos ao cortiço com a nossa provisão de néctar, sem tomar notas, por consequência, nem nos dotarmos por escrito de um tesouro de leitura, sujeitamo-nos a não reter nada, a dispersarmo-nos por diferentes pensamentos e a esquecermo-nos a nós próprios. A escrita, como maneira de recolher a leitura feita e de nos recolhermos sobre ela, é um exercício de razão que se opõe ao grave defeito que a leitura infindável se arrisca a favorecer (FOUCAULT, 1992, p. 133).

Ao pensarmos a arte, o autorretrato em especial, como um processo de escrita de si, afirmamos que o ato de pintar-se, de inserir-se em um contexto pictórico imaginado anteriormente e materializado na tela da artista é parte de um processo de reconhecimento de si, tal qual a escrita. A arte e a pintura são aqui entendidas como uma narrativa são histórias ditas através da imagem. Ao autorretratar-se as mulheres, de modo geral, narram suas histórias, suas vivências e experiências cotidianas que abrangem não apenas um universo totalmente particular, mas suas narrativas pictóricas falam para outras mulheres, criando desse modo um diálogo estreito entre a artista e o espectador, assim como ocorre na escrita e na leitura. Quando as mulheres pintam seus autorretratos, tornam-se autoras de si mesmas, há nisso um processo de desprendimento de si próprio como modo de autorreconstrução. Quando observamos as trajetórias de vida e as pinturas das mulheres artistas é exatamente o processo de autorecosntrução de si que está diante do espectador, elas reexistem, 


\section{HISTÓRIA}

HISTÓRIA DAS MULHERES NA ARTE: AUTORRETRATO COMO ESCRITA DE SI

Fernanda Reis

reinventam, reinscreve-se na história e na vida de um modo outro, portanto, é impossível compreender a obra sem conhecer a autora.

\section{REFERÊNCIAS BIBLIOGRÁFICAS}

BOURDIEU, Pierre. A dominação Masculina. Trad. Maria helena Kühner; $6^{\circ} \mathrm{Ed}$., RJ: Bertrand Brasil, 2009.

CHIARA, Ana. Um corpo que vaza: da série Autobiografias e Autorretratos. CHIARA, Ana; SANTOS, Marcelo; VASCONCELLOS, Eliane (Org.). Corpos diversos. Rio de Janeiro: EdUERJ, 2015.

COLLING, Ana Maria. O currículo de História e as relações de gênero hierarquizadas. Salle. Revista de Educação, Ciência e Cultura v. 15 n. 2 jul./dez. 2010.

ECO, Umberto. A definição de arte; trad. Eliana Aguiar. $1^{\circ}$ Ed. Rio de Janeiro: Record, 2016.

FOUCAULT, Michel. A escrita de si. In: O que é um autor? Lisboa: Passagens. 1992. FOUCAULT, Michel. O corpo utópicol As heterotopias. São Paulo: n. 1 edições, 2013.

GOMBRICH, Ernst Hans. Arte e ilusão: um estudo ela psicologia ela representação pictórica / Trad. Raul ele Sá Barbosa. 3ed. São Paulo: Martins Fontes, 1995.

NIETZSCHE, Frederich. O nascimento da tragédia. Trad. Antônio Carlos Braga; São Paulo. Escala: 2013.

NOCHLIN, Linda. Por que não houve mulheres artistas? Trad. Juliana Vacaro. Publication São Paulo; São Paulo: 2016.

PEIRCE, Charles Sanders. Semiótica. Trad. José Teixeira Coelho Neto. 4 ed. São Paulo: Perspectiva, 2010.

PERROT, Michelle. Minha história das Mulheres. 1. ed. ,São Paulo: Contexto, 2008. TEDESCHI, Losandro Antônio. As mulheres e a história: uma introdução teórico metodológica. Dourados, MS: Ed. UFGD, 2012

TVARDOVSKAS, Luana Saturino. Dramatização dos corpos: arte contemporânea e crítica feminista no Brasil e Argentina. São Paulo: Intermeios, 2015. 